\title{
الإفراج المشروط كأسلوب لإعادة إدماج المحبوسين اجتماعيا في التشريع الجزائري
}

\author{
شعيب ضريف \\ كلية الحقوق " سعيد حمدين " \\ جامعة الجزائر بن يوسف بن خذة
}

مقدّمة:

الأصل أن برامج المعاملة العقابية الهادفة

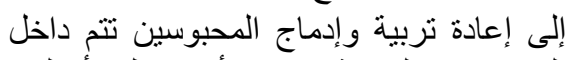

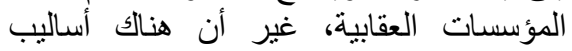

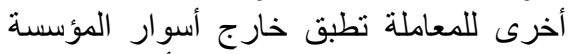
العقابية وتهدف إلى تمهيد السبيل أمام المحبوس المبوس

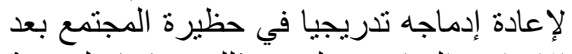

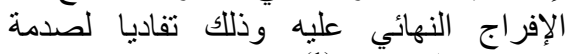

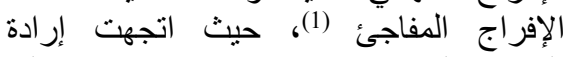

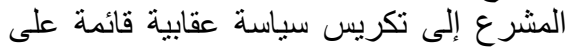

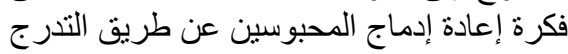

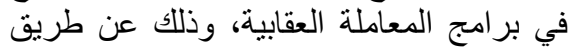

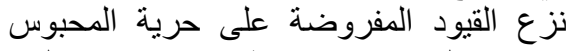
وفرض التزامات وشروط بعد الإفراج علية الئه، تكون الغاية منها وضعات تحت فت فترة إختبار لتأكد

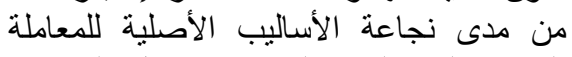
العقابية التي تلقاها المحبوس داخل الإليب المؤسسة العقابية في درئ الخطورة الإجرامية الكامنة

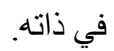

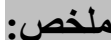

الإفراج المشروط أسلوب من أساليب المعاملة العقابية الهادفة إلى إعادة إدماج المحبوس في المجتمع عن طريق إطلاق سلاق سر احها

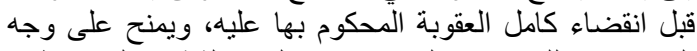

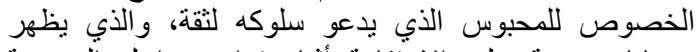
ضمانات جدية على الاستقامة أثناء تواجده داخل ألمؤسسة

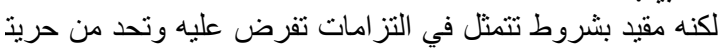

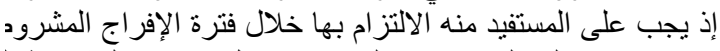

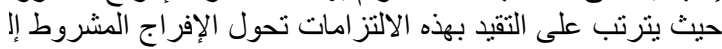

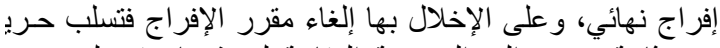

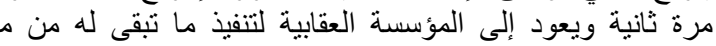
العقوبة. - العية.

الكلمات المفتاحية:

الإفراج المشروطة، إعادة الإدماج المحبوسين، المؤسسة العقابية، المعاملة العقابية، قاضي تطبيق العقوبات.

\begin{abstract}
:
Conditional release is a method of penitentiary treatment that aims to reintegrate prisoners in society by releasing him/her before the completion of his/ her entire sentence period, It granted especially to prisoner of good conduct who shows strong integrity guarantees during his/her existing in a penitentiary institution.

During Conditional release, the beneficiary subjected to terms represented by obligations that imposed on him/her and limit his freedom. Respecting those engagements transform the conditional release to final discharge however breach of any conditions will revoke the release order and return
\end{abstract} him/her to prison to complete his/her sentence. Keywords:

Conditional release ( parole), reintegration of prisoners, The penitentiary institution, penitentiary treatmen, the sentencing judge. 


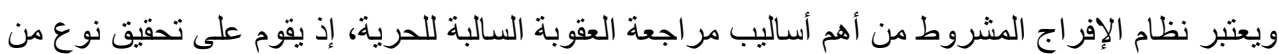

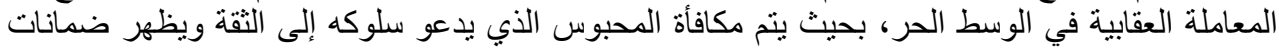

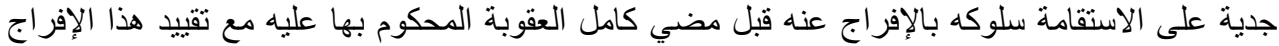

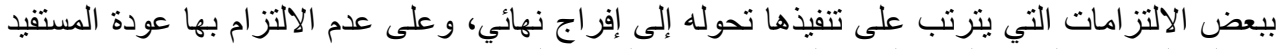

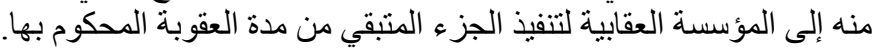

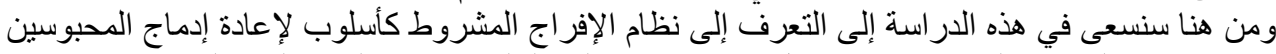

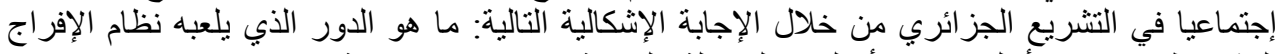

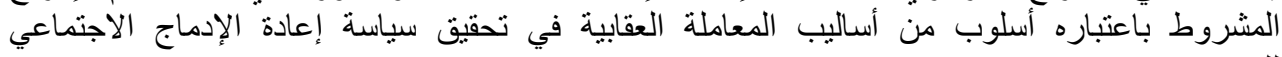

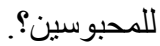
وتتفرع عن هذه الإنشكالية جملة من التساؤلات المهمة عن مفهوم الإفراج المشروط وطبيعته القانونية،

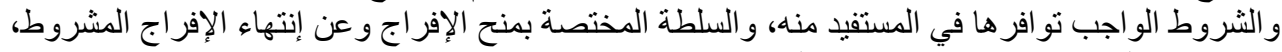

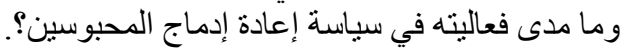
والإجابة على هذه الإشكاليات تكون في مبحثين، نتناول في الأبناج الأول ماهية الإفراج المشروط، أما الثاني

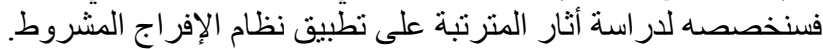

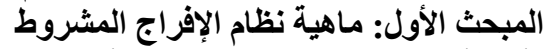

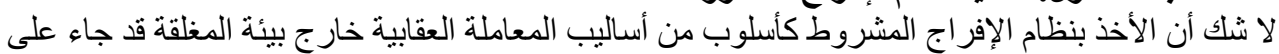

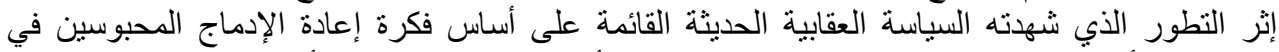

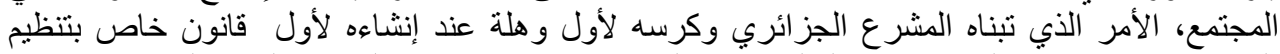

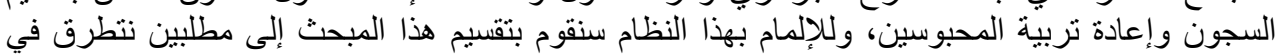

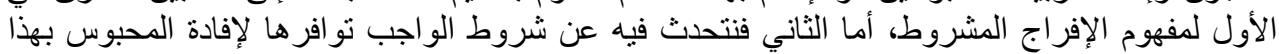

$$
\text { ألمطلب الأول: مفهوم الإفراج المشروط }
$$

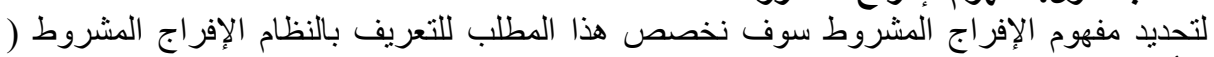

$$
\begin{aligned}
& \text { الفرع الأول )، وتبيان الطبيعة القانونية لنظام الإفراج المشروط ( الفرع الثراجئ الثاني ). }
\end{aligned}
$$

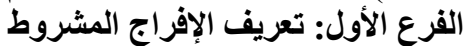

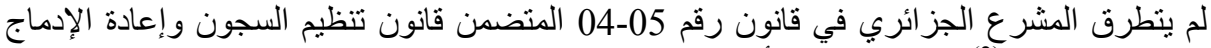

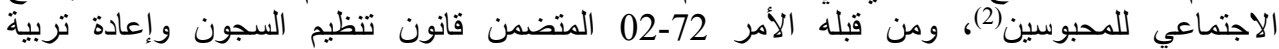

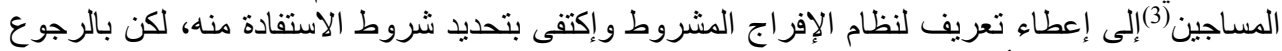
إلى الفقه فقد وردت بشأنه العديد من النعاريف.

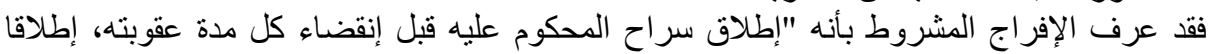

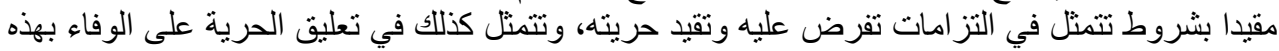

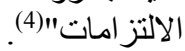

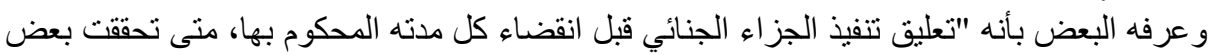

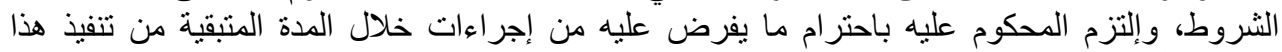

كما يعرف بأنه "نظام يخول للإدارة العقابية الإفراج على المحكوم عليه قبل إنقضاء مدة معينة من إنباء

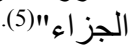

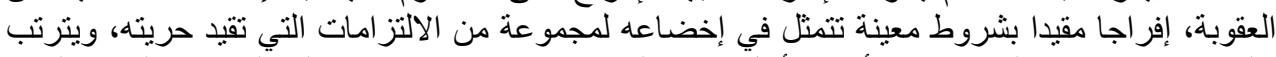
على تتفيذها الإفر اج النهائي عنه، أما إذا أخل بها فتسلب حريته مرة ثانية ويعود إلى ألمؤسسة العقابية لتنفيذ

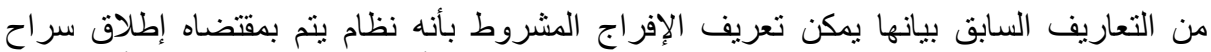

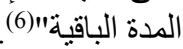

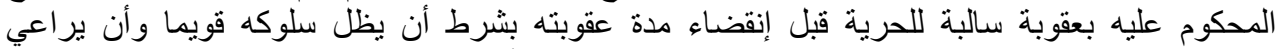

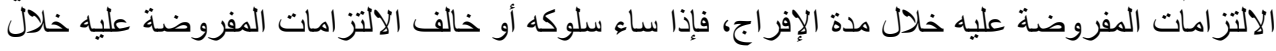


هذه المدة ألغي الإفراج، وبتالي يعود إلى المؤسسة العقابية لقضاء المدة المتبقية من العقوبة، أما إذا انتهت

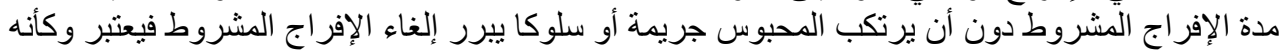
نفذ كل مدة العقوبة.

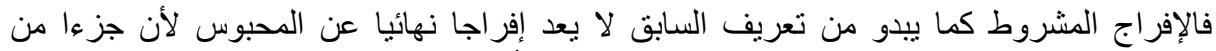

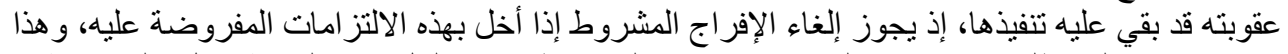

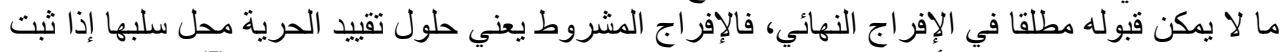

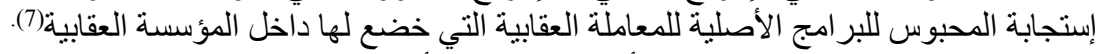

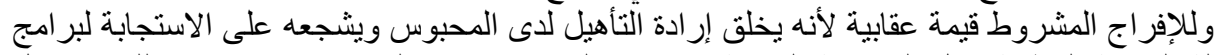

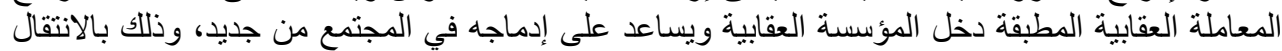

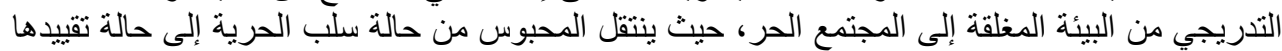

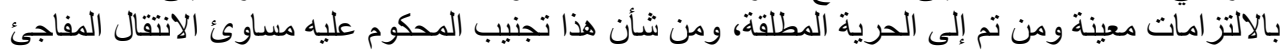

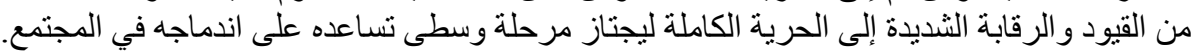

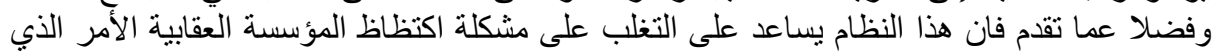

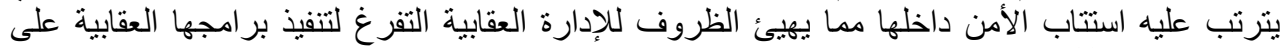

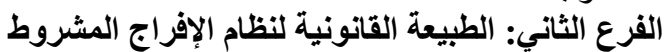
الوجه المطلوب(8).

لقد ثار خلاف بين الفقهاء الفكر العقابي المعاصر حول الطبينة الفيعة القانونية للإفر اج المشروط وانقسموا

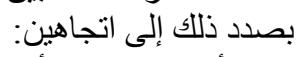

أولا- الاتجاه الأول: يرى أن أن الإفر اج المشروط عمل إداريا لأنه في حقيقته يعدل من المعاملة العقابية

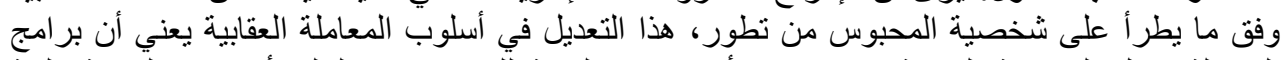

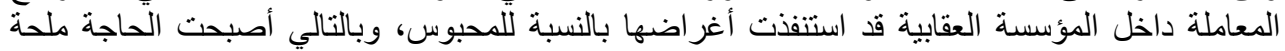

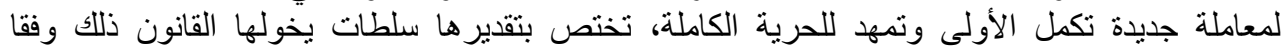

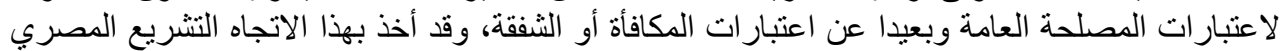

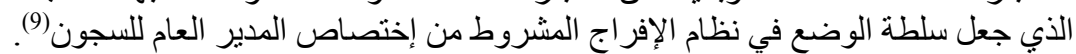

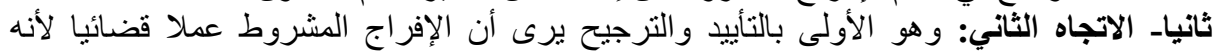

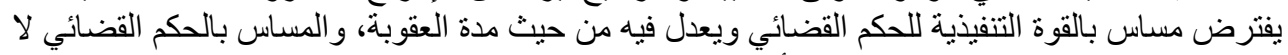

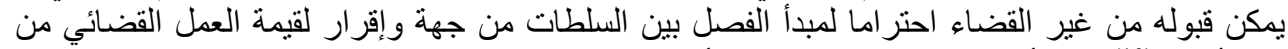

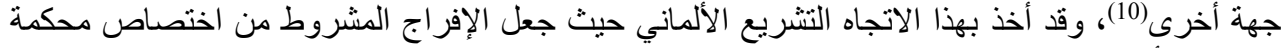

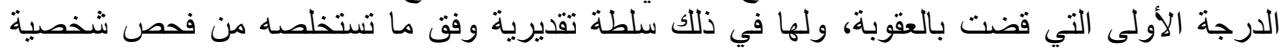

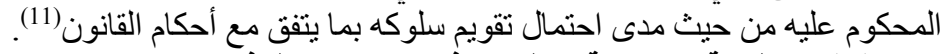

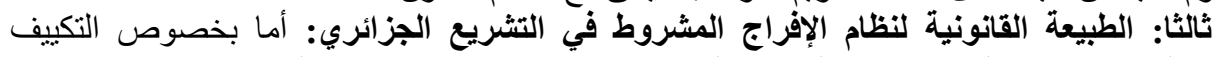

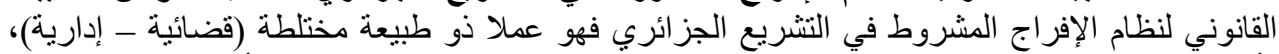

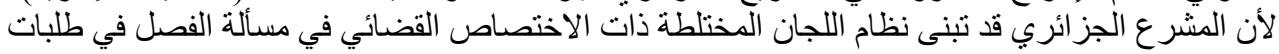

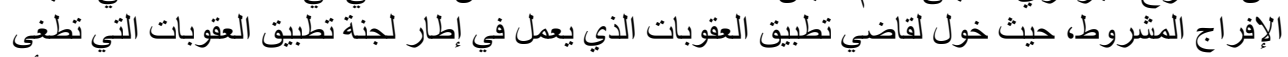

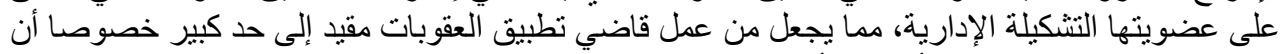

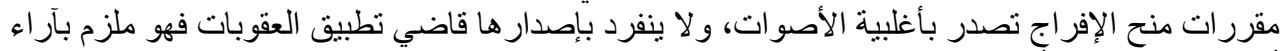

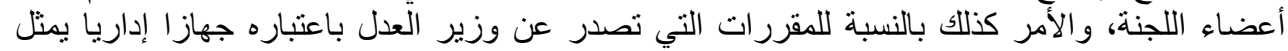

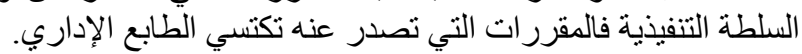

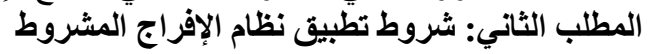

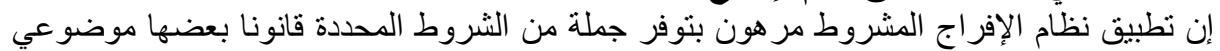

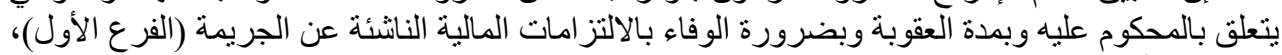
و البعض الأخر شكلي يتعلق بالجهة التي تملك سلطة منح الإفراج (الفرع الثاني). 
الفرع الأول- الثروط الموضوعية:

حددت المادة 134 من قانون 05-04 الثروطة الثروط الموضوعية الواجب توافرها لاستفادة المحبوس من

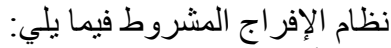

أولا الشروط التئي تتعلق بالمحكوم عليه:

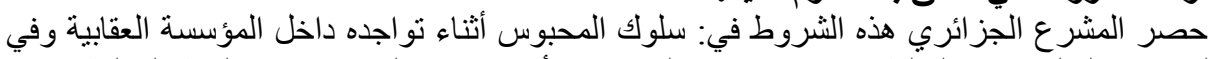

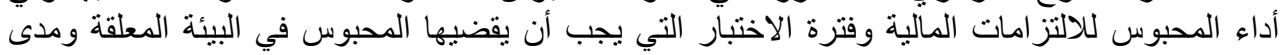
قابليته للاستفادة من مز ايا هذا النظام.

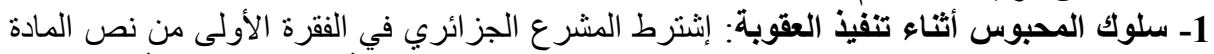

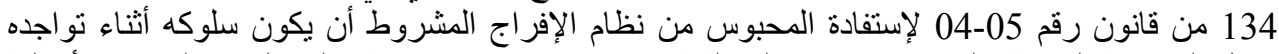

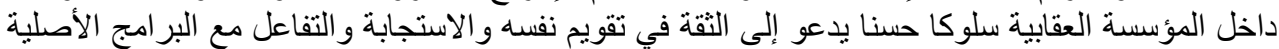

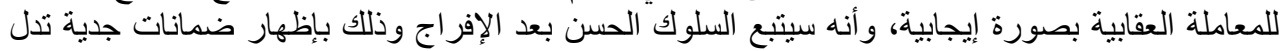
على إستقامته بما لا يدع مجالا للثك على سهولة إندماجه في المجتمع وتكيفه معه بعد استنفاذ فترة تتفيذ

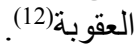

ويتم التحقق من شرط حسن السبرة و السلوك وضمانات الجدية للاستقامة على أيدي القائمين على إدارة

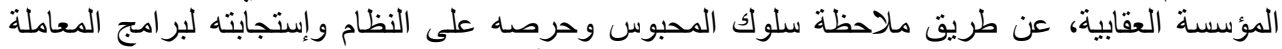

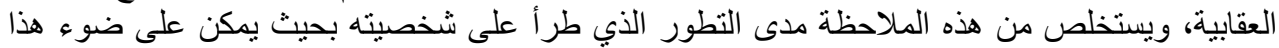

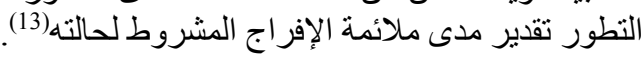

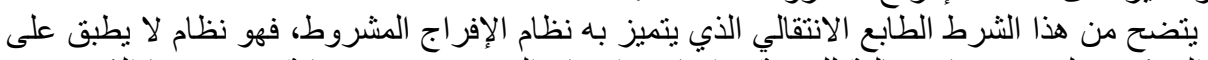

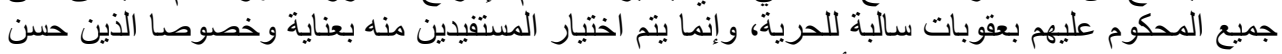

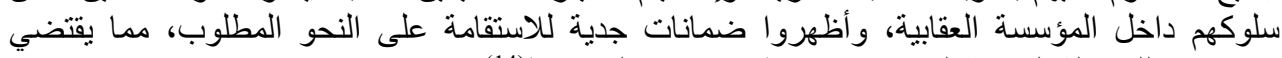

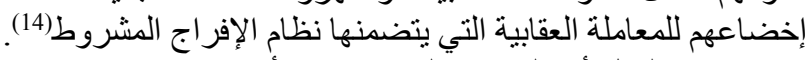

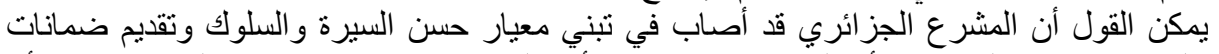

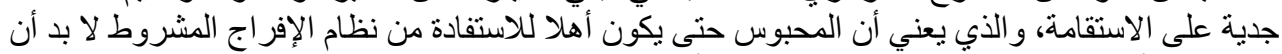

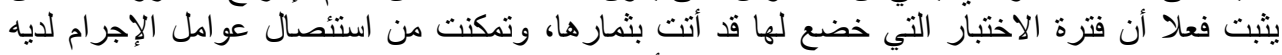

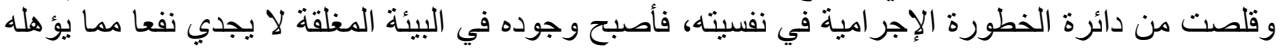
ل اللاستفادة من الإفر اج المشروط.

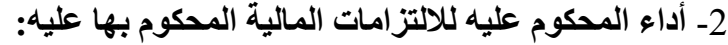

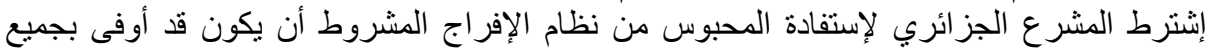

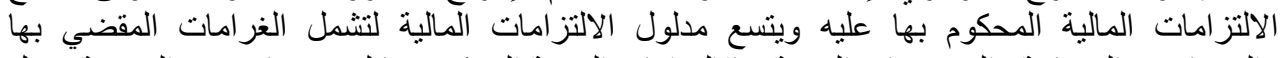

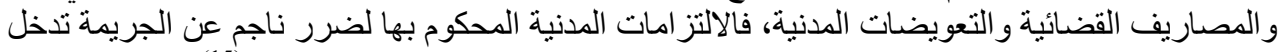

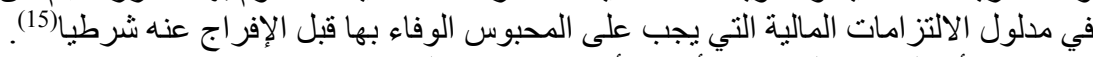

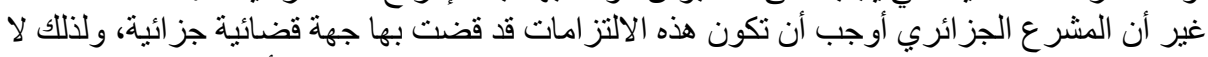

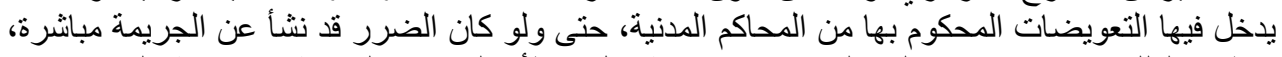

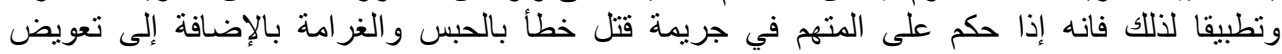

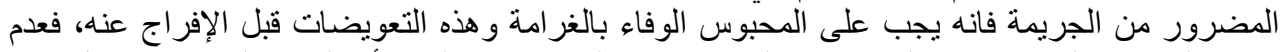

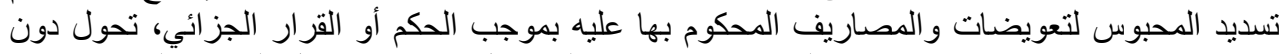

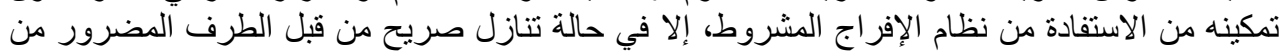

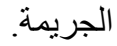

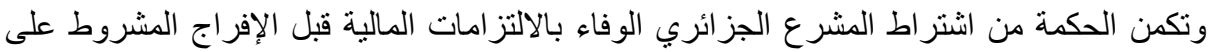

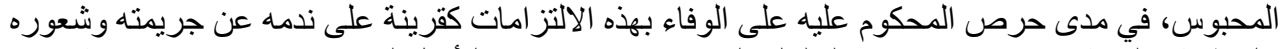

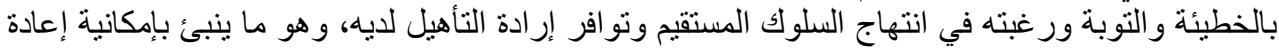
تكيفه في المجتمع بعد الإفر اج عليه. 


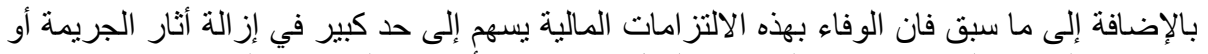

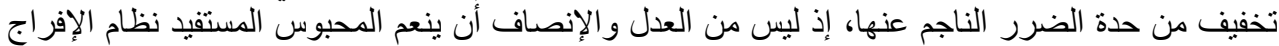

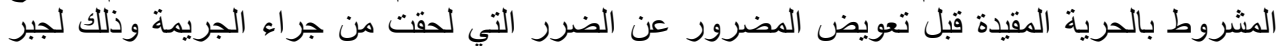

وفي هذا الصدد يثور تسأل حول وضع المحبوس الذي بستحيل عليه الوفاء بالالتزامات المالية

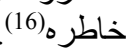

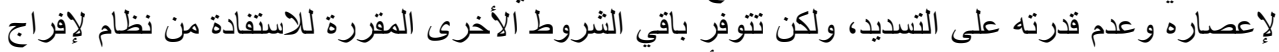

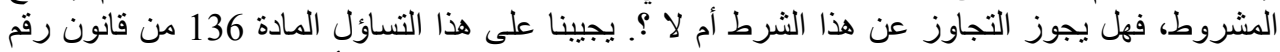

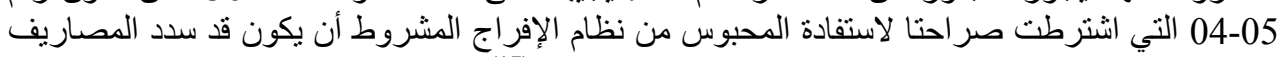

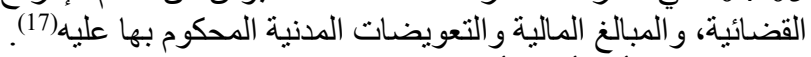

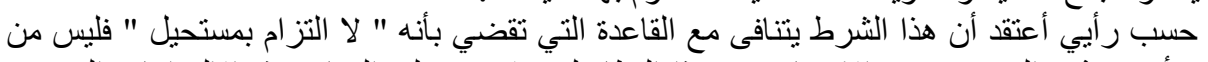

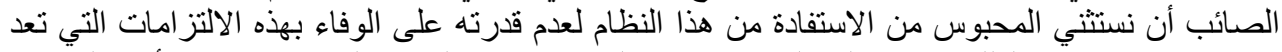

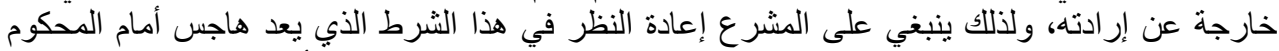

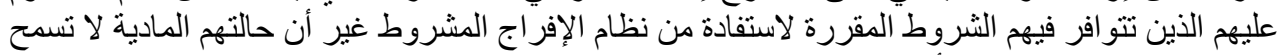

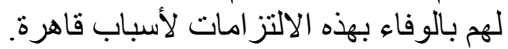

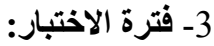

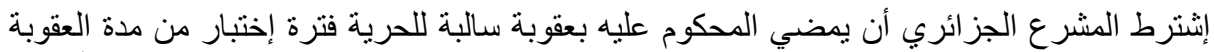

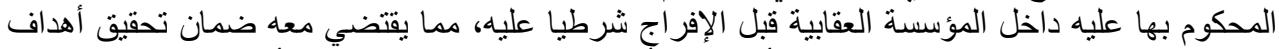

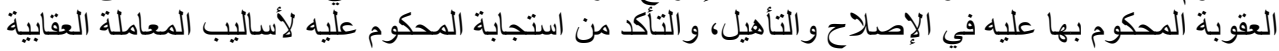

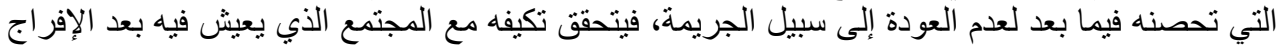
عنه نهائيا.

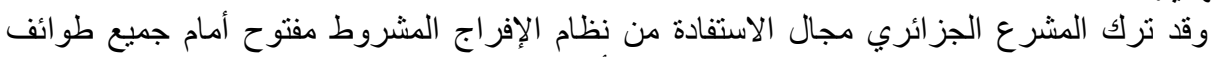

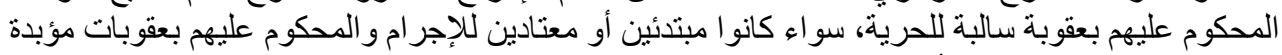

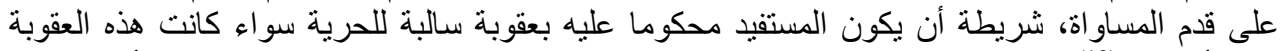

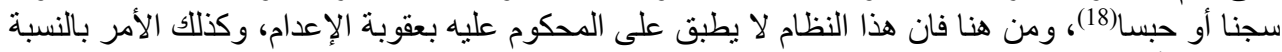

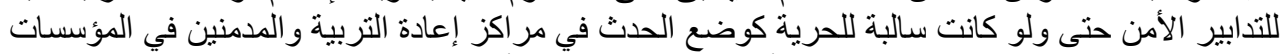

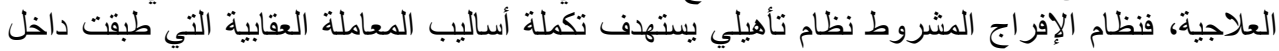

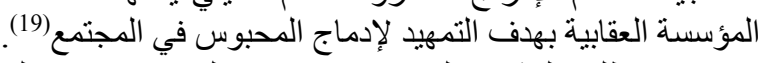

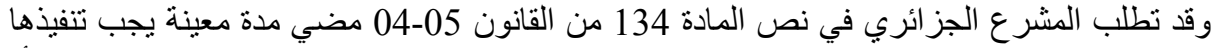

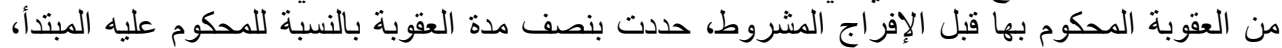

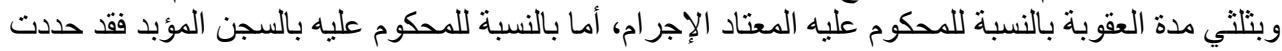
بمدة 15 سنة.

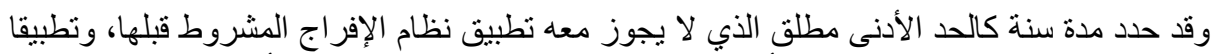

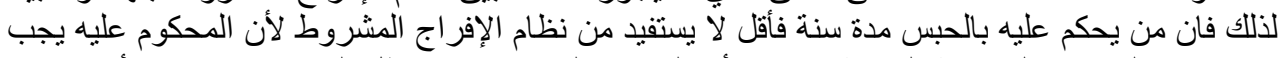

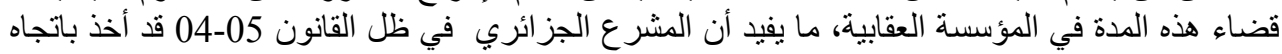
الفقهي الذي ينادي بعدم تطبيق نظام الإفر اج المشروط الفئ على المحبوسين التحكوم عليهم بعقوبات سالبة للحرية

لا يفوتنا في هذا المقام الإشارة إلى أن مدة الحبس التي تلؤخذ بعين الاعتبار لحساب فترة الاختبار قصبرة المدةث) (20).

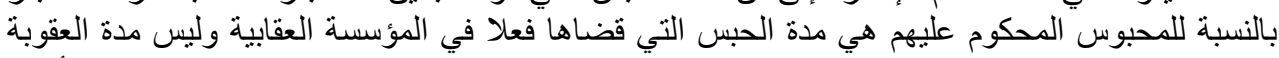

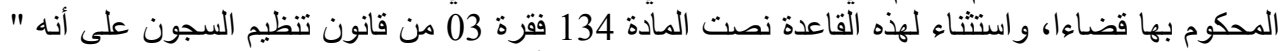

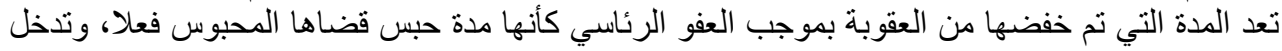
ضمن حساب فترة الاختبار، وذللك فيما عدا حالة المحبوس المحكوم عليه بعقوبة السجن المبان المؤبد ". 


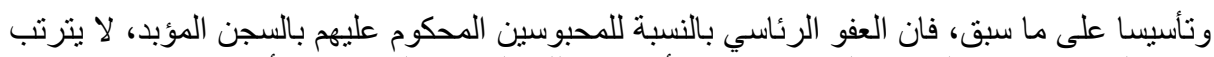

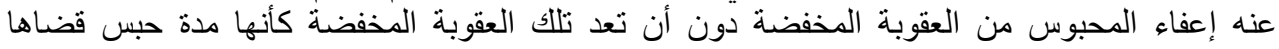

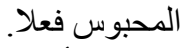

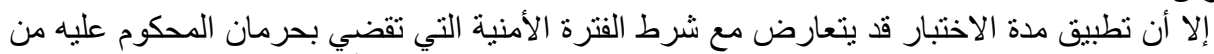

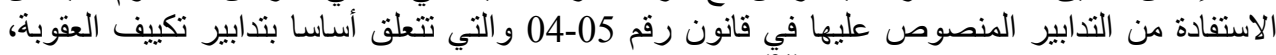
وتدابير إعادة التربية خارج البيزية البئة المغلقة (21).

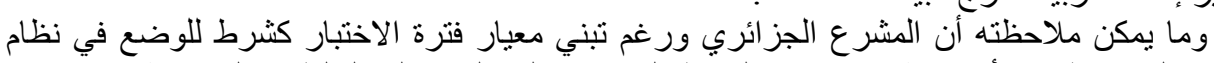

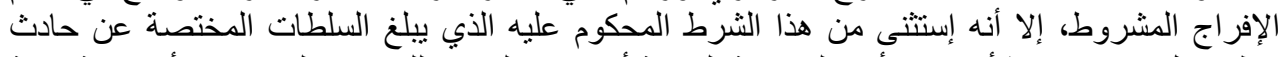

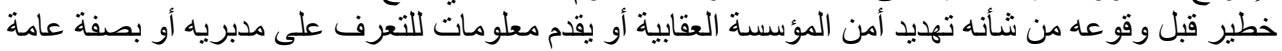
يكثف عن مجرمين و وإيقافه (22).

وفي هذا الصدد يثور إثكال حقيقي بخصوص إمكانية إعفاء المحبوس الذي يبلغ السلطات عن جريمة

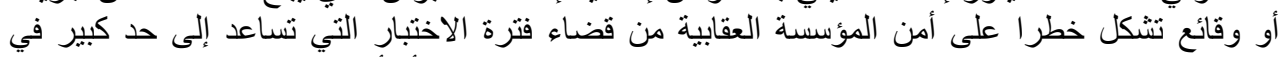

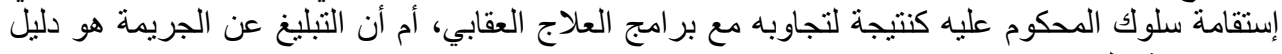

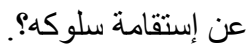

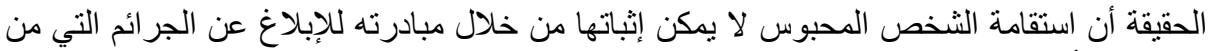

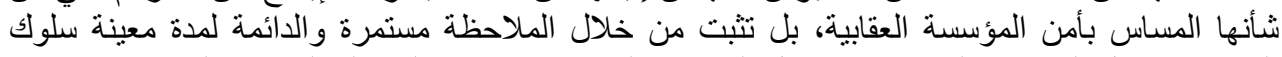

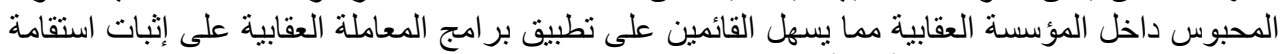

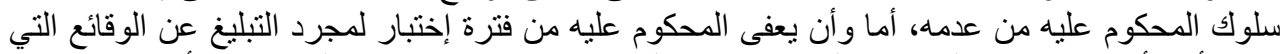

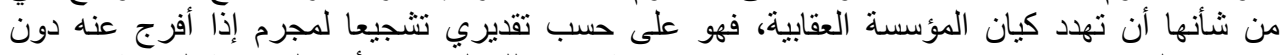

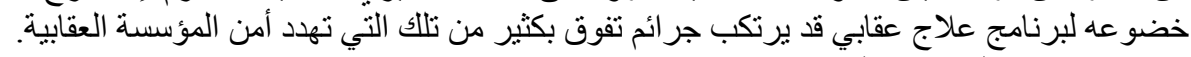
4- 1 - 1ضاء المحكوم عليه:

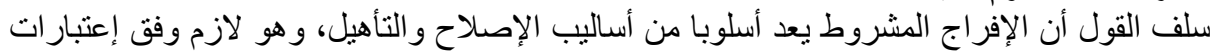

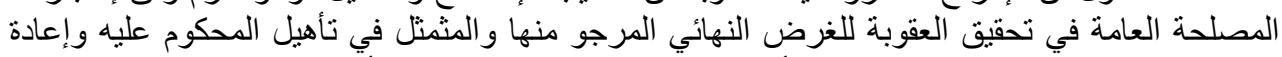

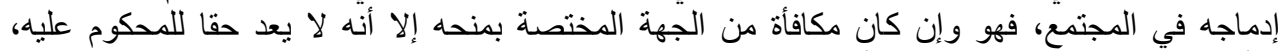

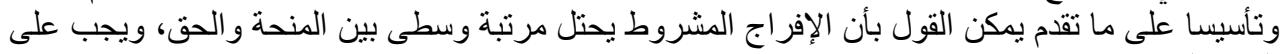

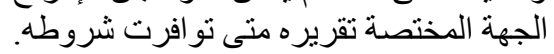

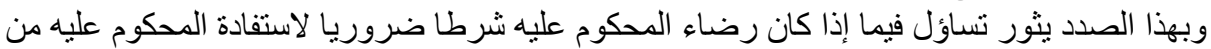

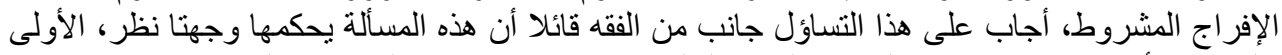

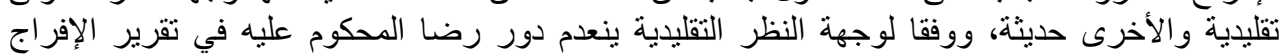

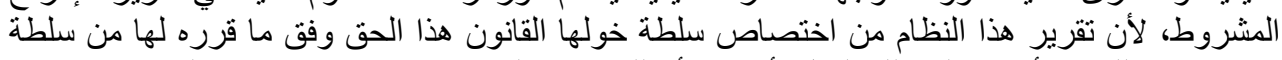

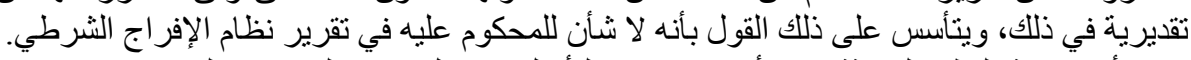

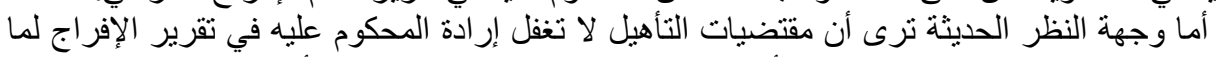

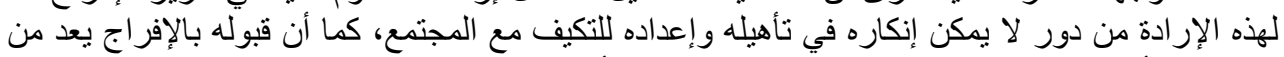

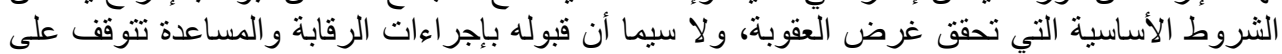

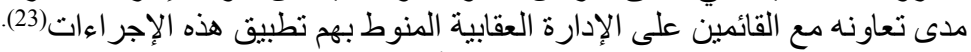
اشترط المشرع الجزائري في ظلإنل الأمر

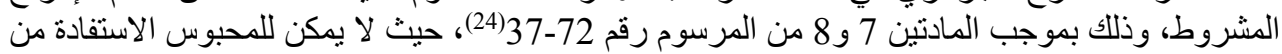

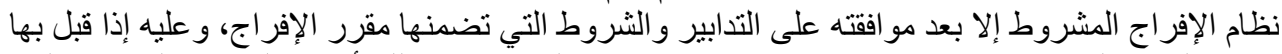

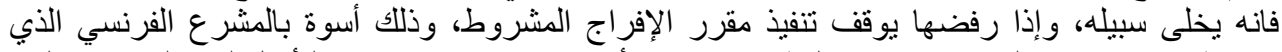

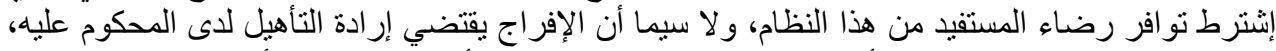

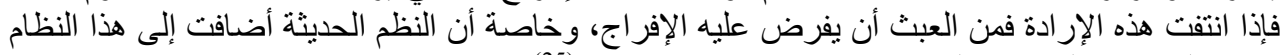
تدابير المر اقبة و المساعدة التي تطبق في فترة ما بعد الإفراج(إن (25). 


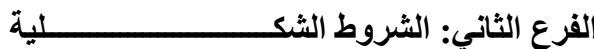

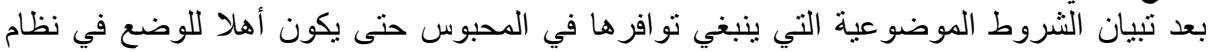

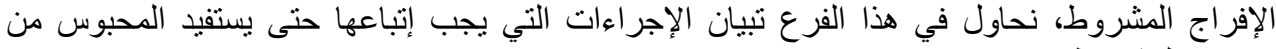

\section{أولا- اختصاص قاضي تطبيق العقوبات للفصل في طلبات الإفراج المشروط:}

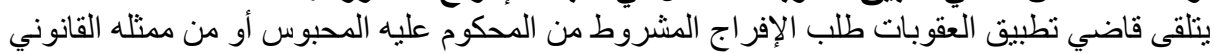

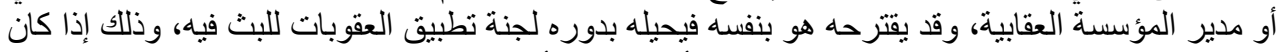

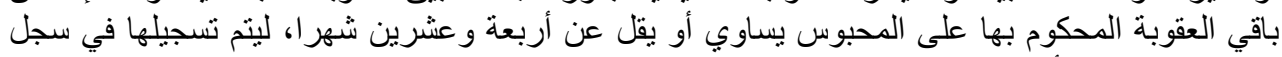

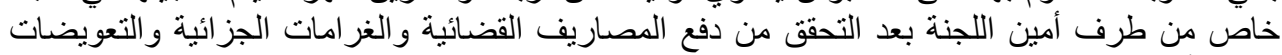
المدنية أو ما يثبت النتازل عنها.

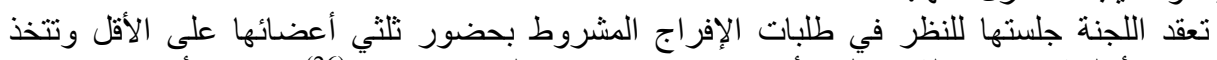

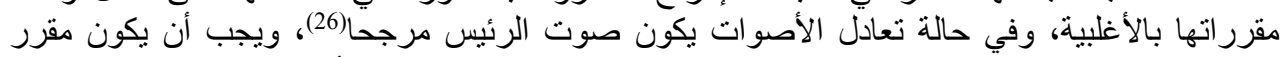

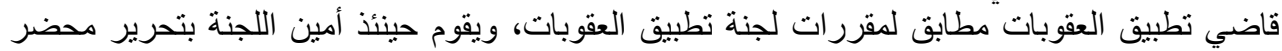

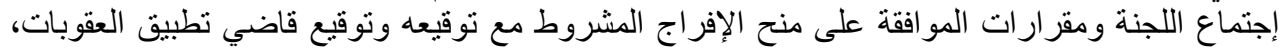

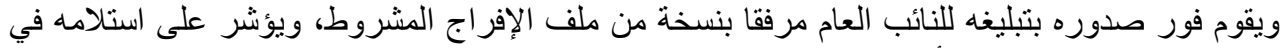
سجل التبليخات المتداول بين أمانة اللجنة و النيابة العامة.

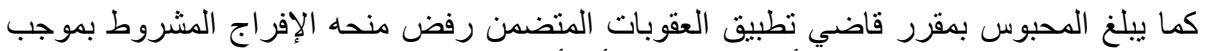

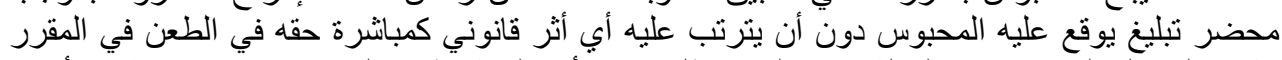

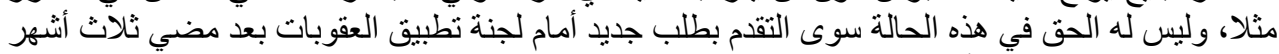

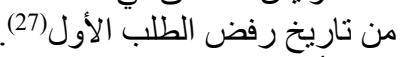

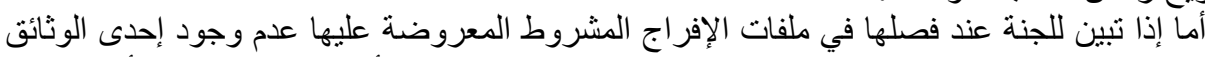
المكونة للملف، يجوز لها إرجاء الفصل فيه إلى غاية إتمام الملف شريطة أن لا تتجاوز مدة التأجيل شهرا

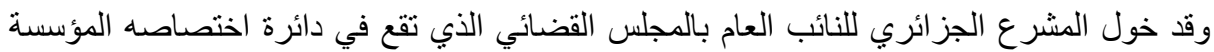

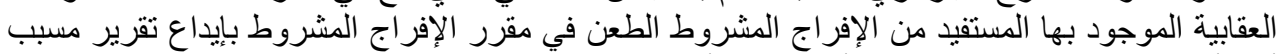

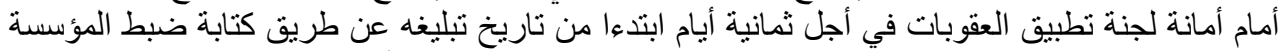

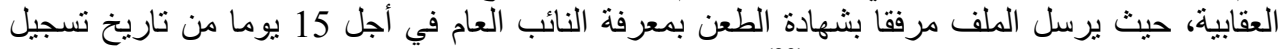

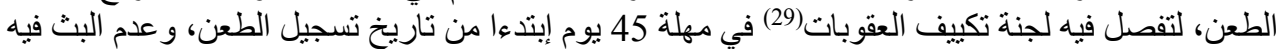

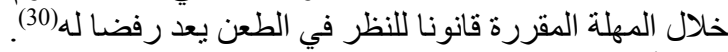

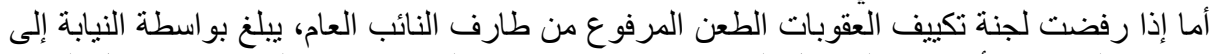

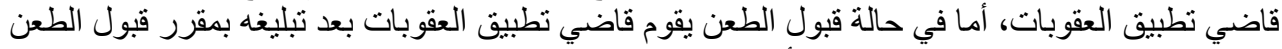

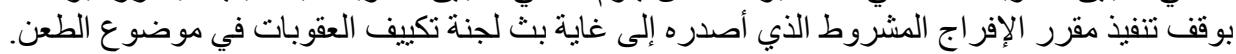

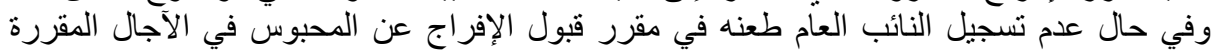

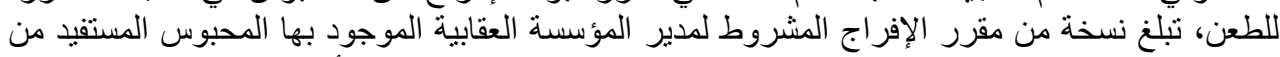

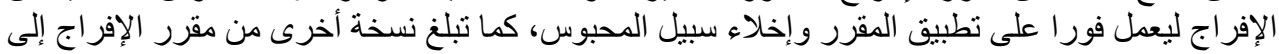

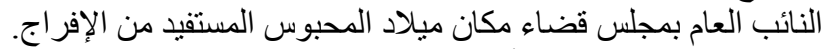

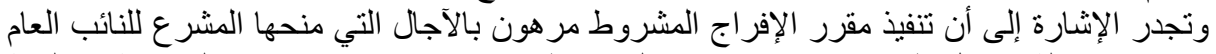

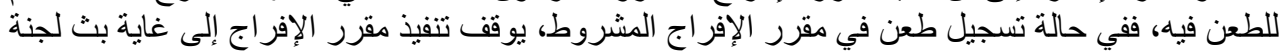

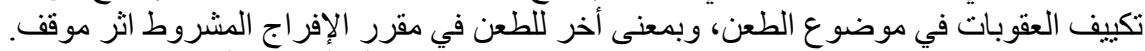

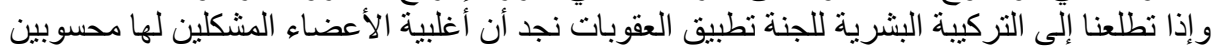

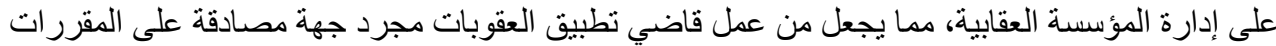
التي يتداولها أعضاء اللجنة، خصوصا إذا كنا نعلم بأن المقررات التي يتخذها قاضي تطبيق العقوبات يجب التبات 


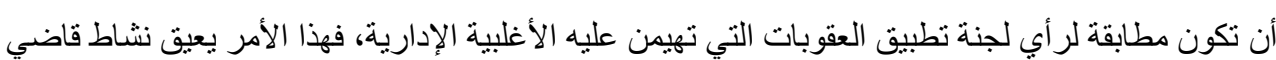

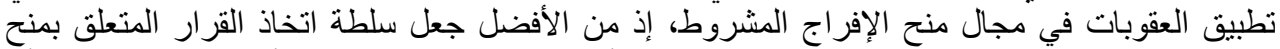

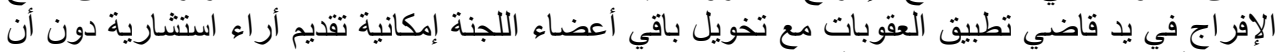

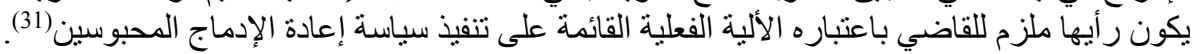

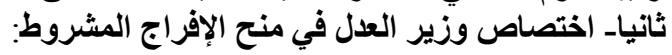

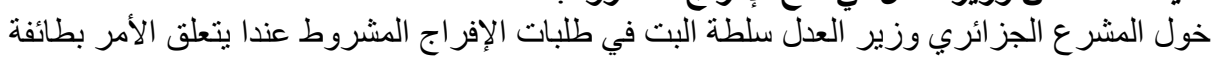

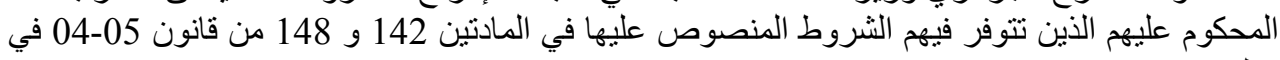
حالتين:

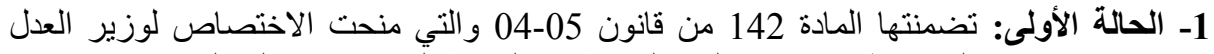

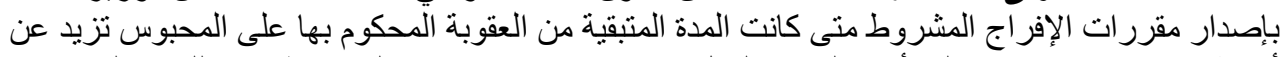

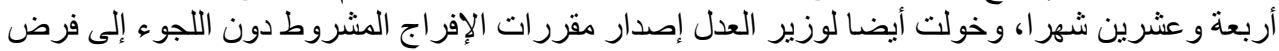

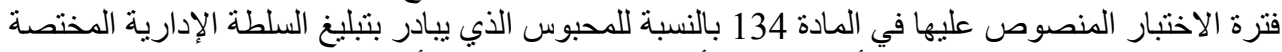

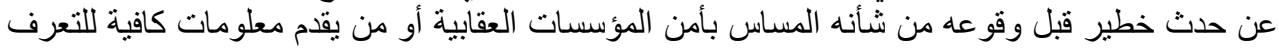

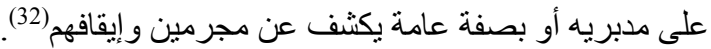

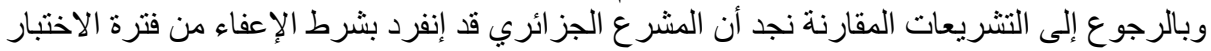

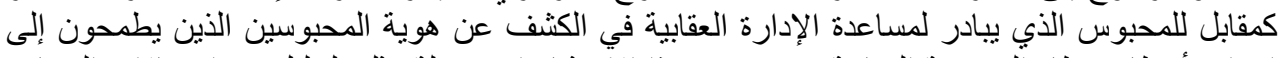

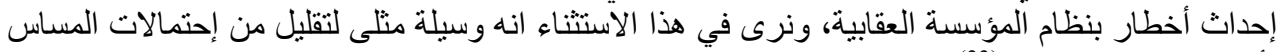

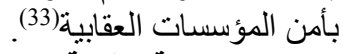
2- الحالة الثانية: استحدث المشرع الجزائية ائري بموجب المادة 148 من قانون 05-04 حكما خاصا

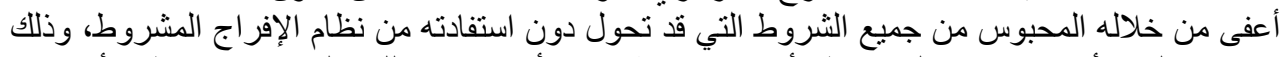

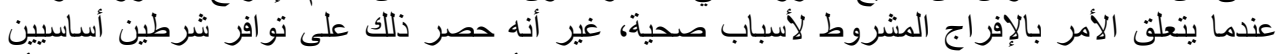

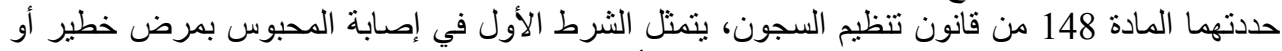

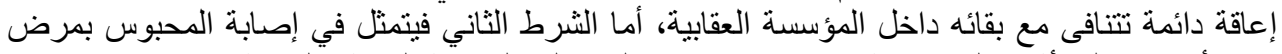

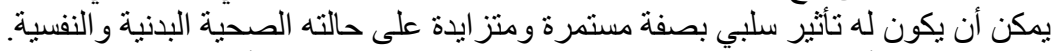

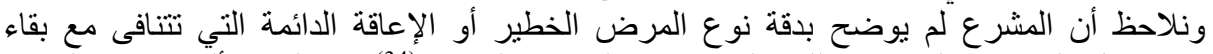

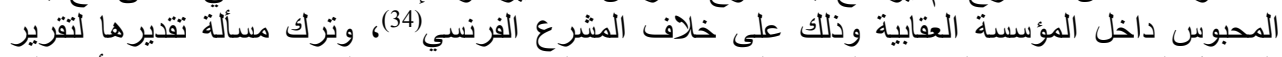

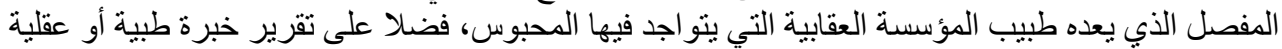

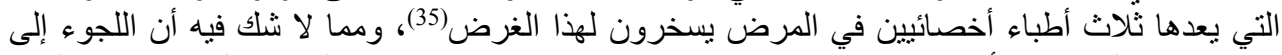

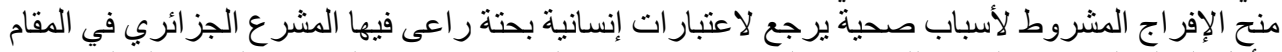

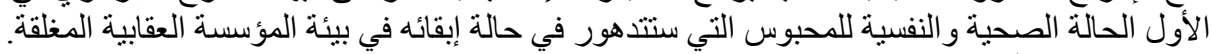

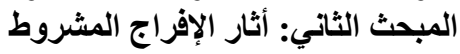

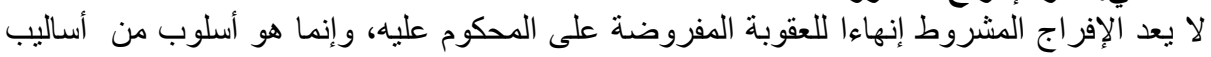

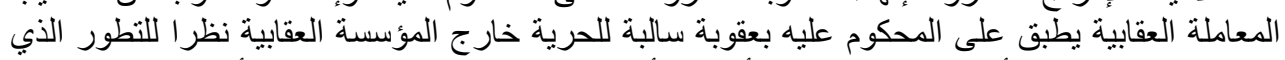

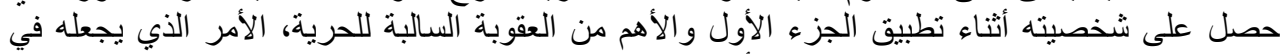

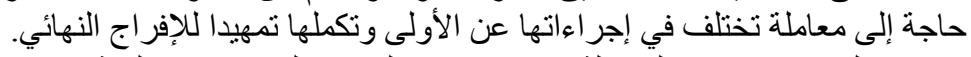

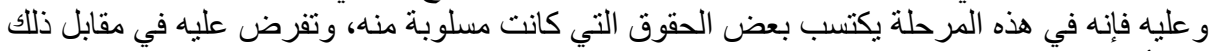

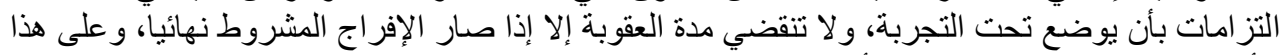

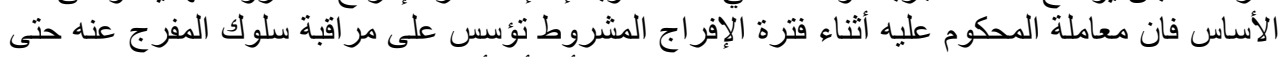

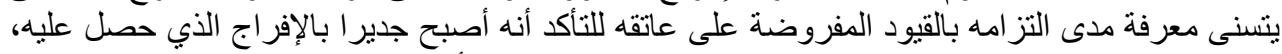

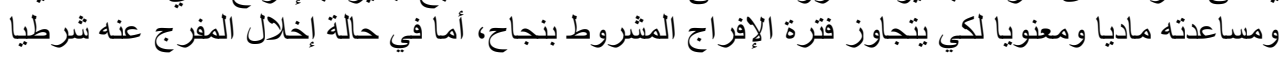

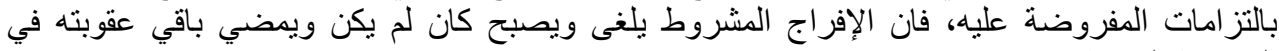


وتتمثل الآثار المترتبة على الإفراج المشروط في تدابير المر اقبة والمساعدة المفروضة على المفرج

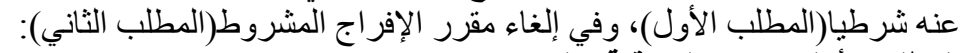

المطلب الأول: تدابير المراقبة والمساعدة اللغاءة

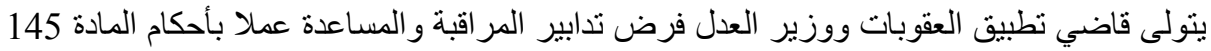

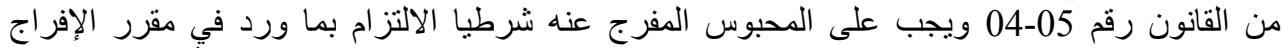

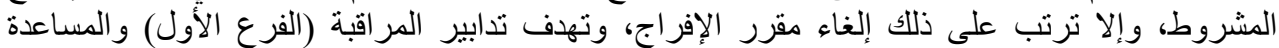

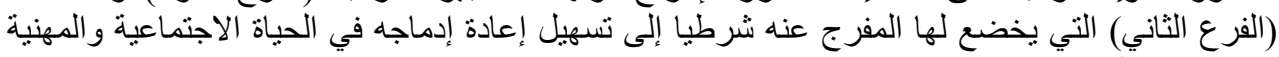

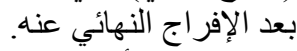

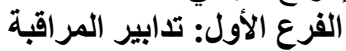

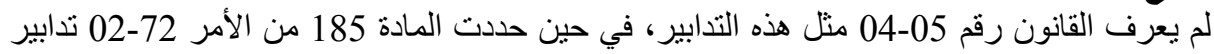

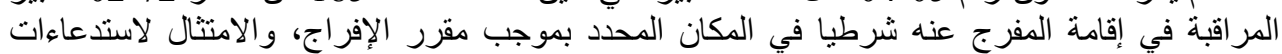

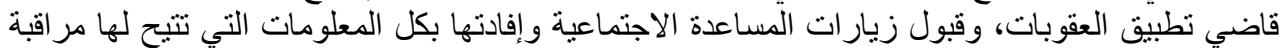

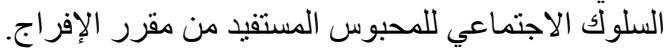

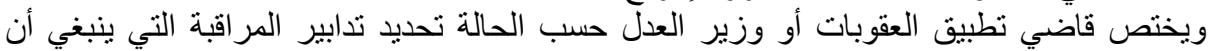

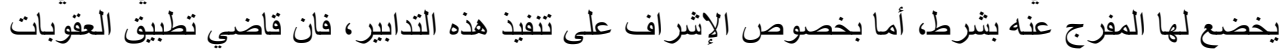

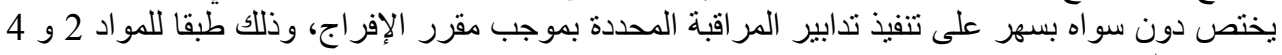

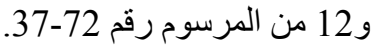

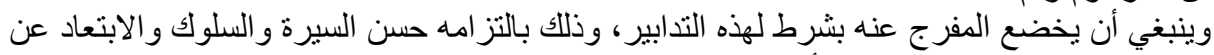

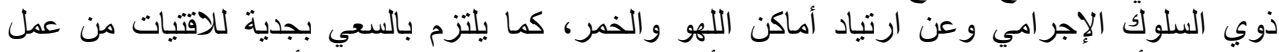

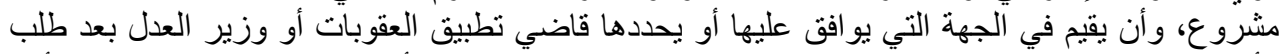

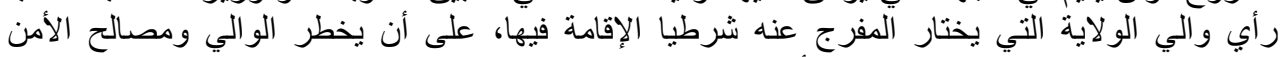

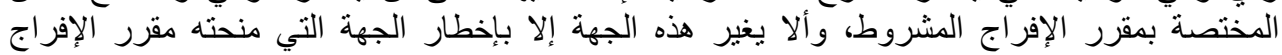

الفرع الثاني: تدابير المساعدة (المشروط

يتولى وزير العدل وقاضي نطبيق العقوبات ـ حسب الحالة ـ تحديد تدابير المساعدة الاجتماعية التي

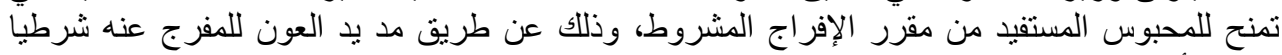

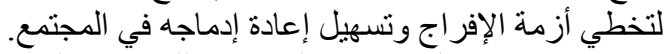

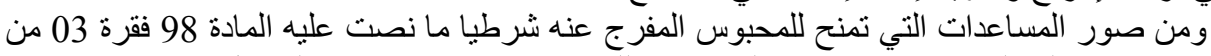

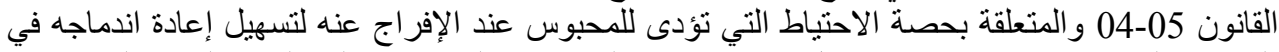

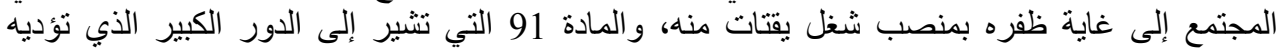

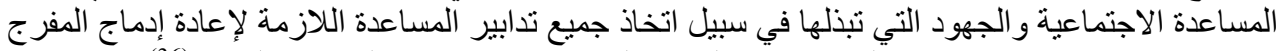

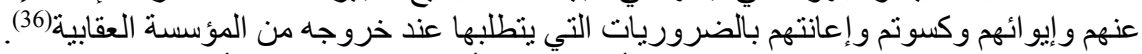

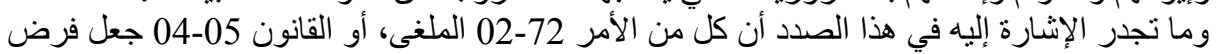

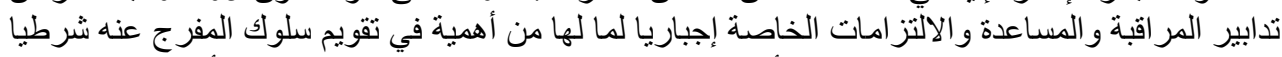

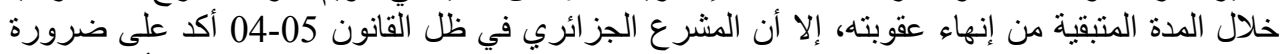

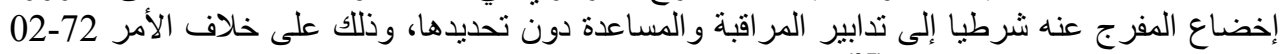
الذي كان يحدد طبيعة هذه التدابير (37) التئ.

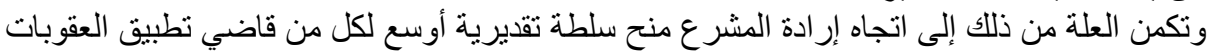

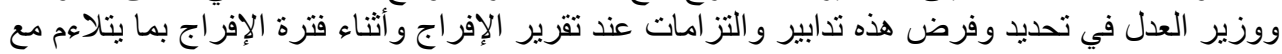
شخصية المفرج عنه شريطا. وتطبيقا لذلك فقد قررت المادة 146 من القانون رقم يخالف المفرج عنه شرطيا الالتزامات المفروضة إلى غاية التاريخ الذي كان الأن مقررا لانتهاء مدة العقوبة نهابة 


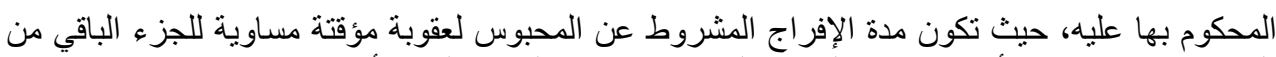

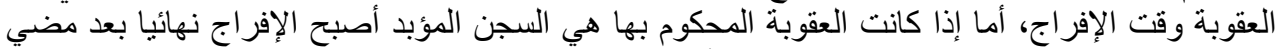

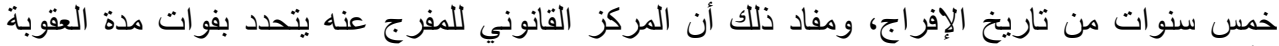

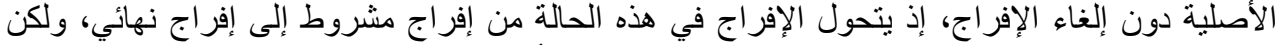

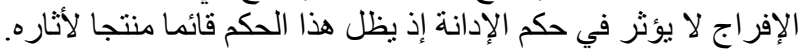

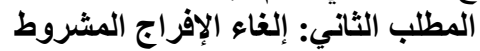

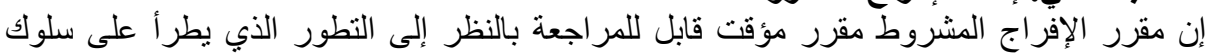

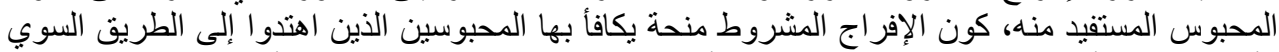

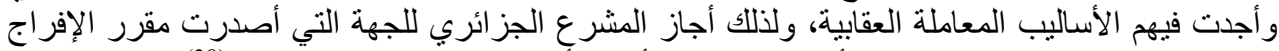

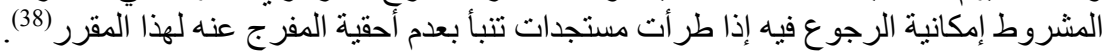

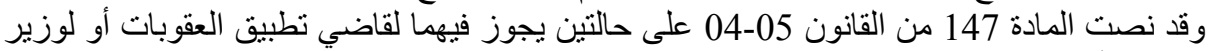

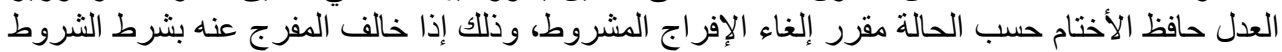
التي وضعت للإفراج ولم يقم بالالتزامات المفروضة الإنة ( الفرع الأول )، أو إذا صدر في حقه حكم جديد

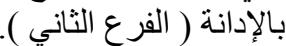

الفرع الأول: إخلال المحبوس بالالتزامات المفروضة عليه

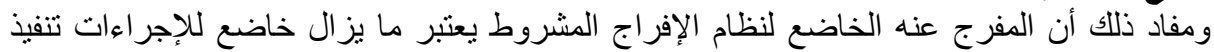

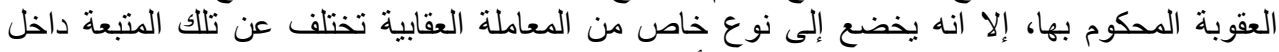

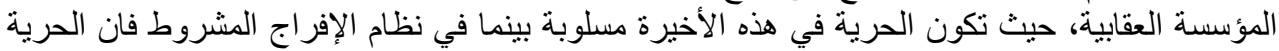

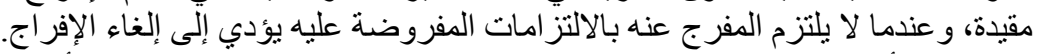

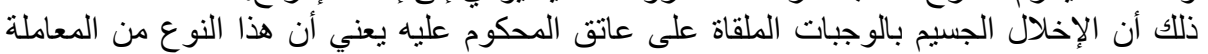

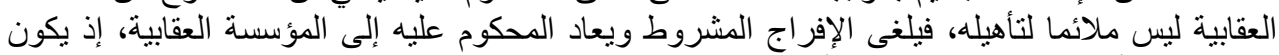

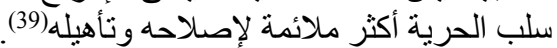

الفرع الثاني: صدور حكم جديد بالإدادية

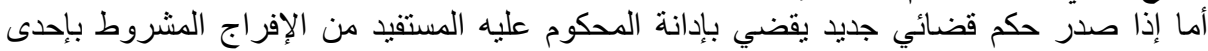

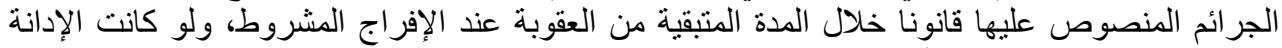

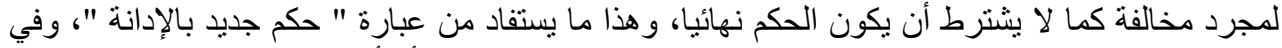

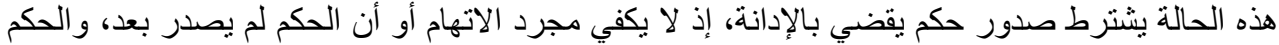

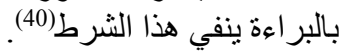

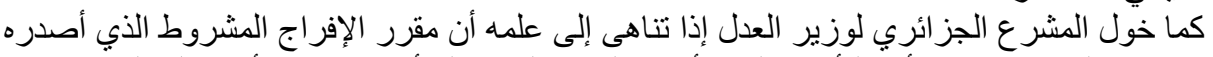

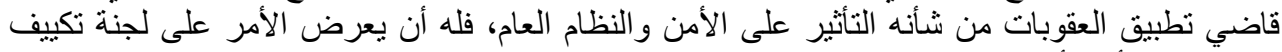

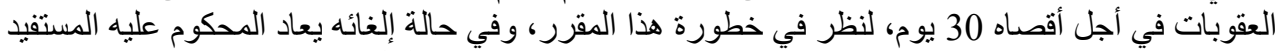

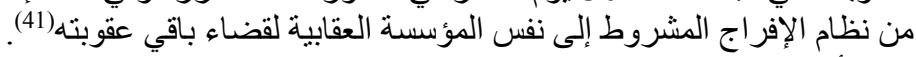

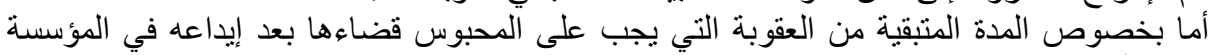

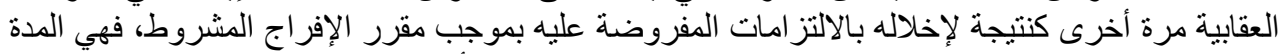

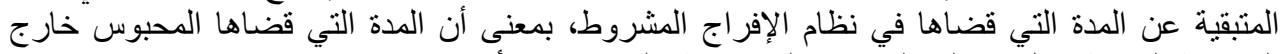

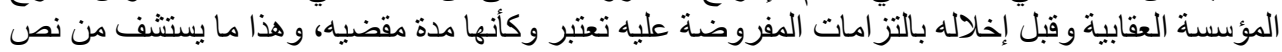

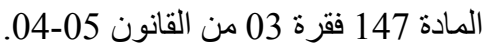

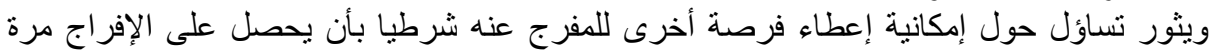

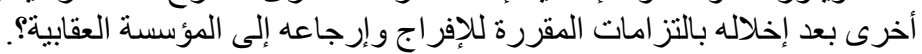

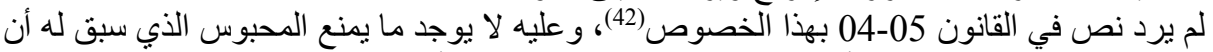

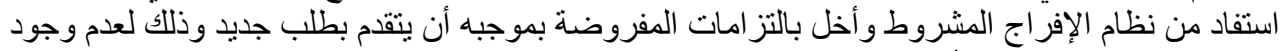
ما يمنع ذلك صرحتا، غير أن السلطة المختصة بمنح الإفر اج المشروط سترفض بصفة تلقائية طلب الإفراج 


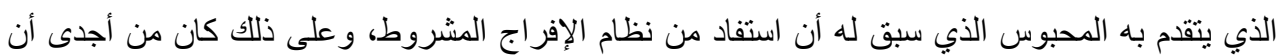

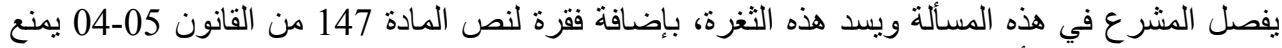

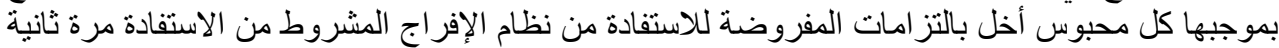

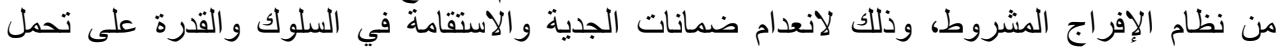

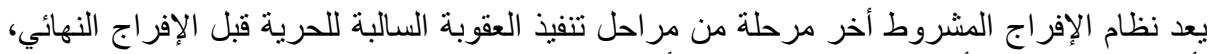

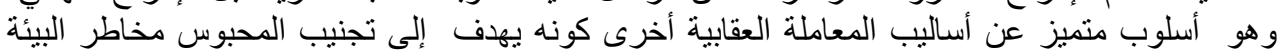

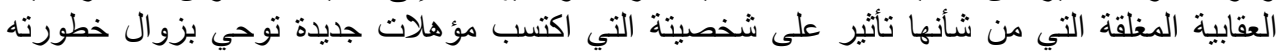

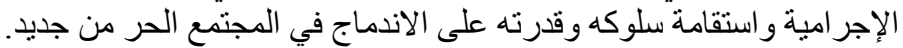

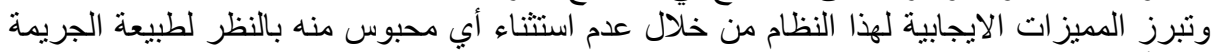

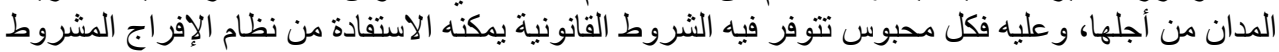

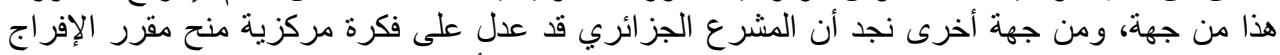

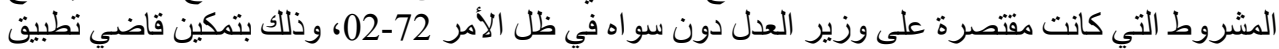

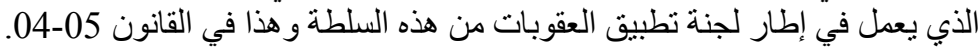
ومن أجل تفعيل دور الإفراج المشروط كأسلوب لإعادة إدماج المحبوسين إجتماعيا نقترح بعض إنس

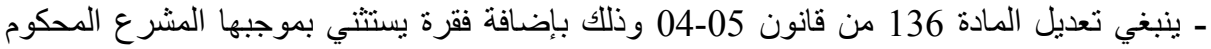
عليهم الذين لا بستطيعون الوفاء بالالتزامات المالية الدفروضة عليهم لإعصار هم و عدم قدرنهم على الوفاء

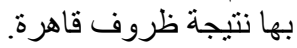
ـ ينبغي تعديل المادة 137 من القانون 04-04 و إنشتر اط مو افقة المحبوس كثرط أساسي للإستفادة من

نظام الإفراج المشروط. - ينبخي إسناد أمر إصدار مقرر الإفراج المشروط لقاضي تطبيق العقوبات دون سواه، وأن تكون أراء

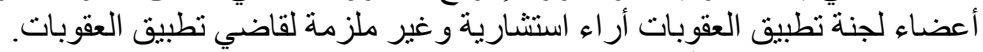

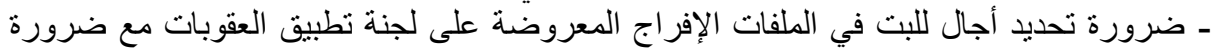

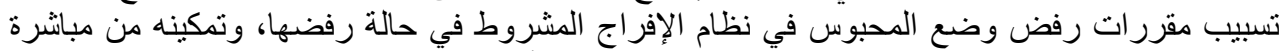

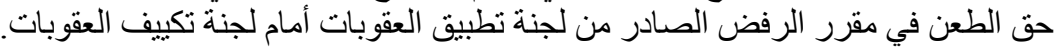

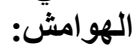

(1)- خوري عمر، الإفر اج المشروط كوسيلة لإعادة إدماج المحبوسين إجتماعيا، المجلة الجزائرية للعلوم

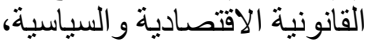

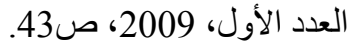

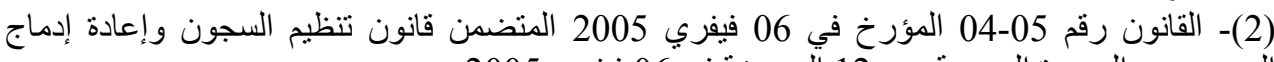

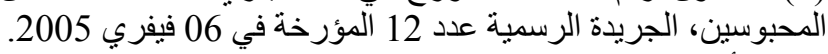

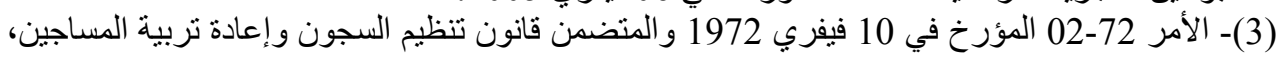

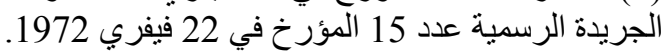
(4)- محمود نجيب حسني، دروس في علم الإجرام والعقاب، دار النهضة العربية، القاهرة، 1988،

(1)- شريف سيد كامل، علم العقاب، دار النهضة العربية، القاهرة، ص358.

(6)- G. Stefani - G. Levasseur et R. Jambu- Merlin criminologie et science

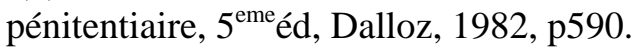

(7)- عبد المعطي عبد الخالق، مبادئ علم العقاب، دار النهضة العربية، القاهرة، 2013، ص338. 
(8)- أسامة عبد الله قايد، مبادئ علم الإجرام و علم العقاب، الطبعة الثانية، دار النهضة العربية، القاهرة،

(10)- خوري عمر، المرجع السابق، ص477.

(10)- أحمد بلال عوض، محاضرات في الجزاء الجنائي، دار النهضة العربية، القاهرة، 2000-2001،

(11)- B. Bouloc, pénologie - exécution des sanction adultes et mineurs - 2 eme éd, Dalloz, paris, 1998, p252.

$$
\text { (12)- - عبد المعطي عبد الخالق، المرجع السابق، ص341. }
$$

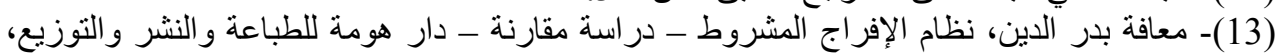

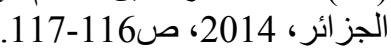

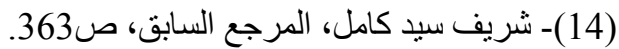

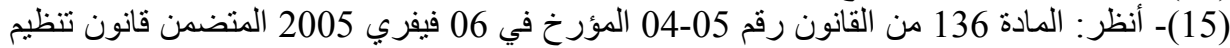

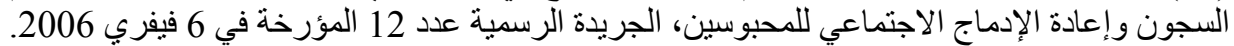

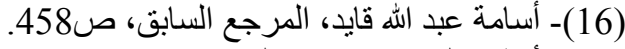

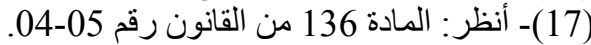

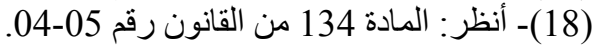

(19)-G. Stefani - G. Levasseur et R. Jambu- Merlin, op.cit, p590.

(20)- أحسن بوسقيعة، الوجيز في القانون الجزائي العام، الطبعة 14، دار هومة للطباعة والنشر

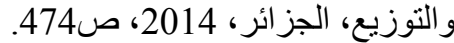

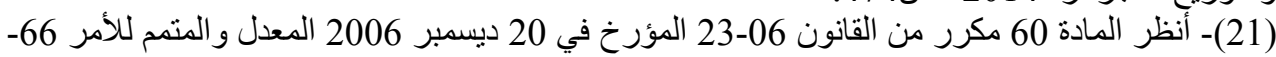

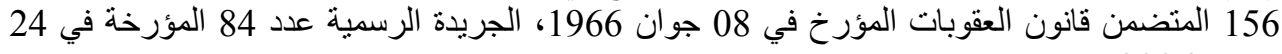
ديسمبر 2006.

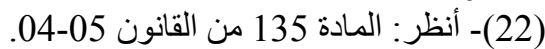

(23)- محمد أبو العلا عقيدة، أصول علم العقاب ـ دراسة تحليلية نأصيلية للنظام العقابي المعاصر

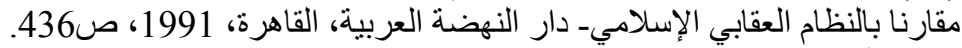

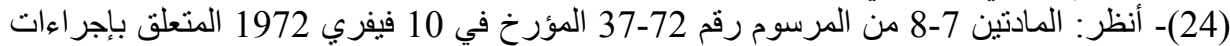

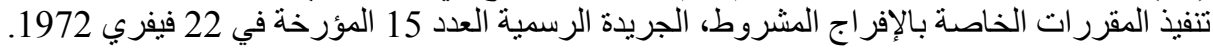
(25)- محمد عيد الغريب، الإفراج الثرطي في ضوط الإن السياسة العقابية الحديثة، دار الإيمان للطباعة،

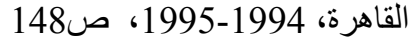

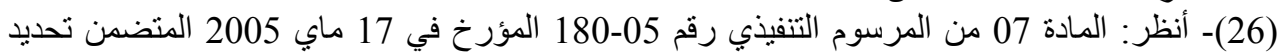

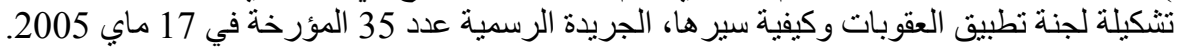

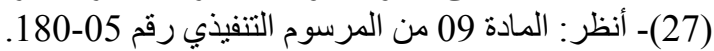
(28)- انظر: التعليمة رقم السجون و إعادة الإدماج.

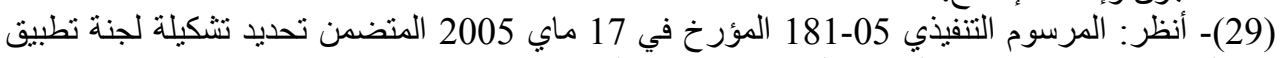

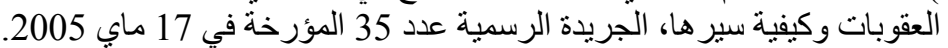
(30)ـ أنظر: المنشور الوز اري 05-01 المؤرخ في 05 جوان 2005 المتعلق بكيفية البث في ملفات الإفراج

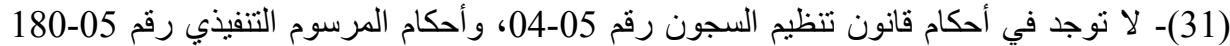

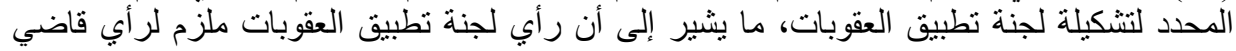

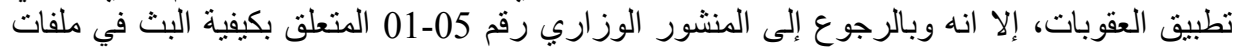
الإفر اج المشروط، نجده يلزم قاضي تطبيق العقوبات بآر اء لجنة تطبيق العقوبات. 
(32)- أنظر : المادة 135 من القانون رقم 05-04.

(33)- بريك الطاهر، فلسفة النظام العقابي في الجزائر وحترة وحقوق السجين، دار الهذى للطباعة والنشر

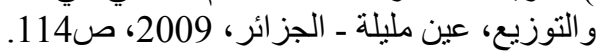

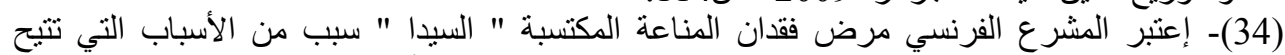

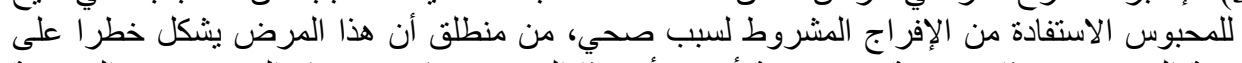

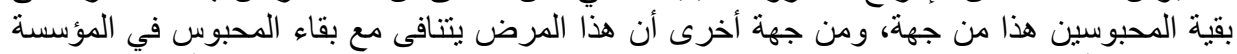

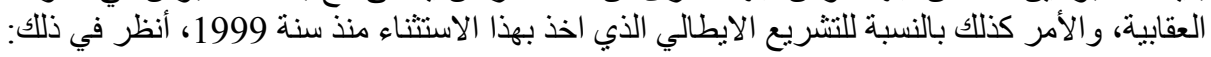

- olivia cligman, Laurence gratiot, jean- Christoph Hanoteaux, le droit en prison, Dalloz, paris, 2001, p118.

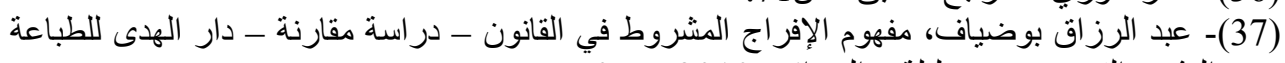

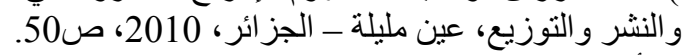

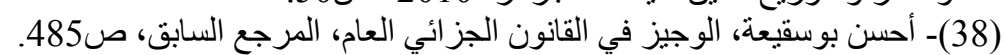

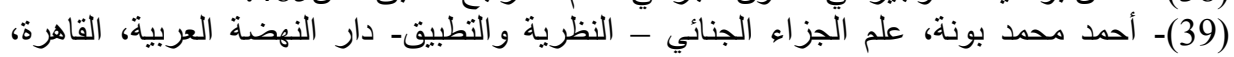

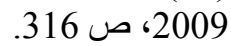

$$
\begin{aligned}
& \text { (40)-عبد الرزاق بوضياف، مفهوم الإفر اج المشروط في القانون، المرجع السابق، ص51. }
\end{aligned}
$$

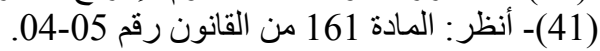

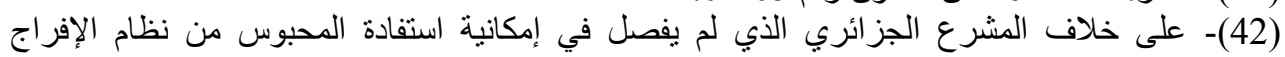

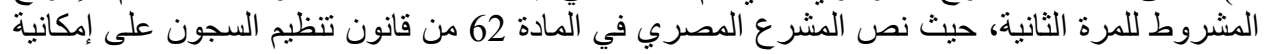

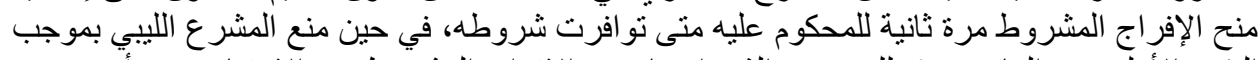

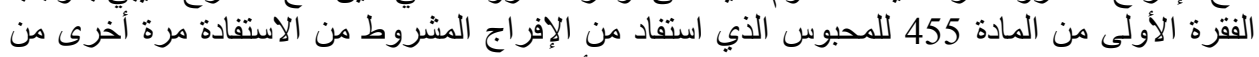

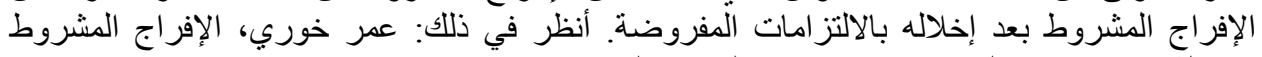

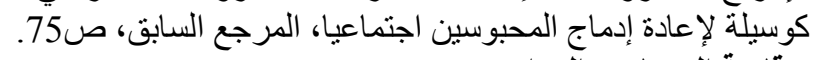

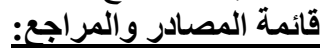

1- أحسن بوسقيعة، الوجيز في القانون الجز ائي العام، الطبعة 14، دار هومة للطباعة و النشر و التوزيع،

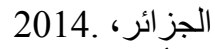

2- أحمد بلال عوض، محاضر ات في الجز اء الجنائي، دار النهضة العربية، القاهرة، 2000-2001.

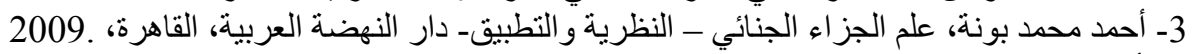
4- أسامة عبد الله قايد، مبادئ علم الإجرام و علم العقاب، الطبعة الثنانية، دار النهضة العربية، القاهرة، 1990

5- بريك الطاهر، فلسفة النظام العقابي في الجزائر وحقوق السجين، دار الهايى للطباعة والنشر

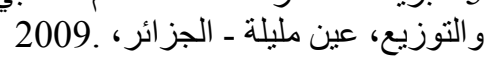
6- خوري عمر ، الإفر اج المشروط كائر، كوسيلة لإعادة إدماج المحبوسين اجنماعبا، المجلة الجزائرية للعلوم

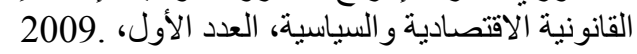
7- شريف سيد كامل، علم العقاب، دار النهضة العزبة العربية، القاهرة، بذون سنة النشر.

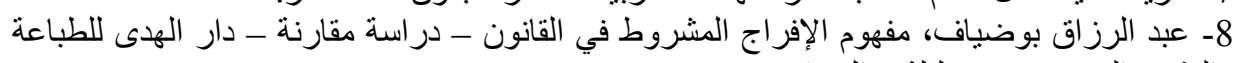

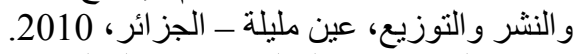

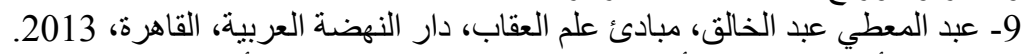

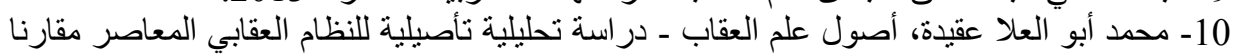
بالنظام العقابي الإسلامي- دار النهضة العربية، القاهرة، .1991 العنابة 
11- محمد عيد الغريب، الإفراج الشرطي في ضوء السياسة العقابية الحديثة، دار الإيمان للطباعة،

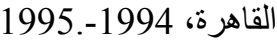

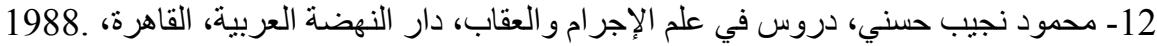

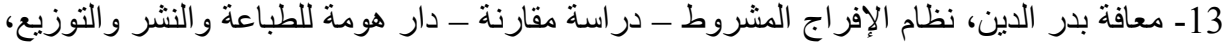

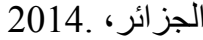

14- القانون رقم 05-04 المؤرخ في 06 فيفري 2005 المتضمن قانون تنظيم السجون و إعادة الإدماج

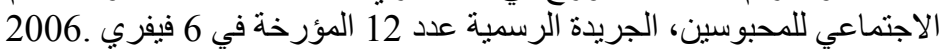

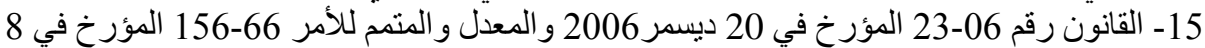

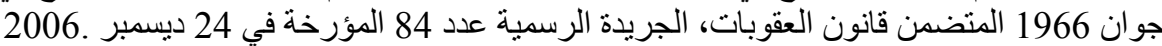

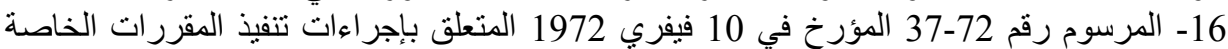

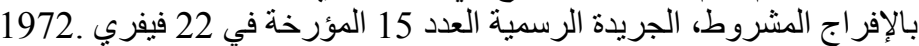

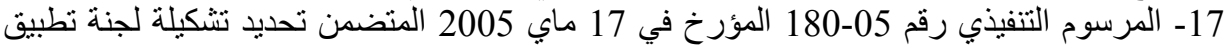

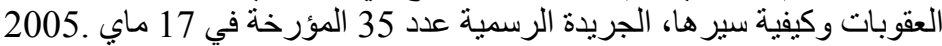

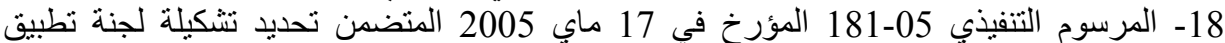

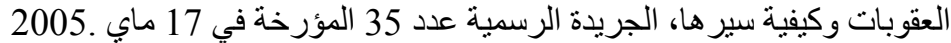
19- المنشور الوزاري 05-01 المؤرخ في 05 جوان 2005 المتعلق بكيفية البث في ملفات الإفراج ، 03 ماي 2005 الصـادرة عن المبر العام لادارة السجون و إعادة الإدماج.

21- Bernard Bouloc, pénologie - exécution des sanction adultes et mineurs - 2 eme éd, Dalloz, paris, 1998.

22- G. Stefani - G. Levasseur et R. Jambu- Merlin, criminologie et science pénitentiaire, $5^{\mathrm{eme} e}$, Dalloz, 1982.

23- olivia cligman, Laurence gratiot, jean- Christoph Hanoteaux, le droit en prison, Dalloz, paris, 2001. 